Have students' feelings of belonging at school waned over time?

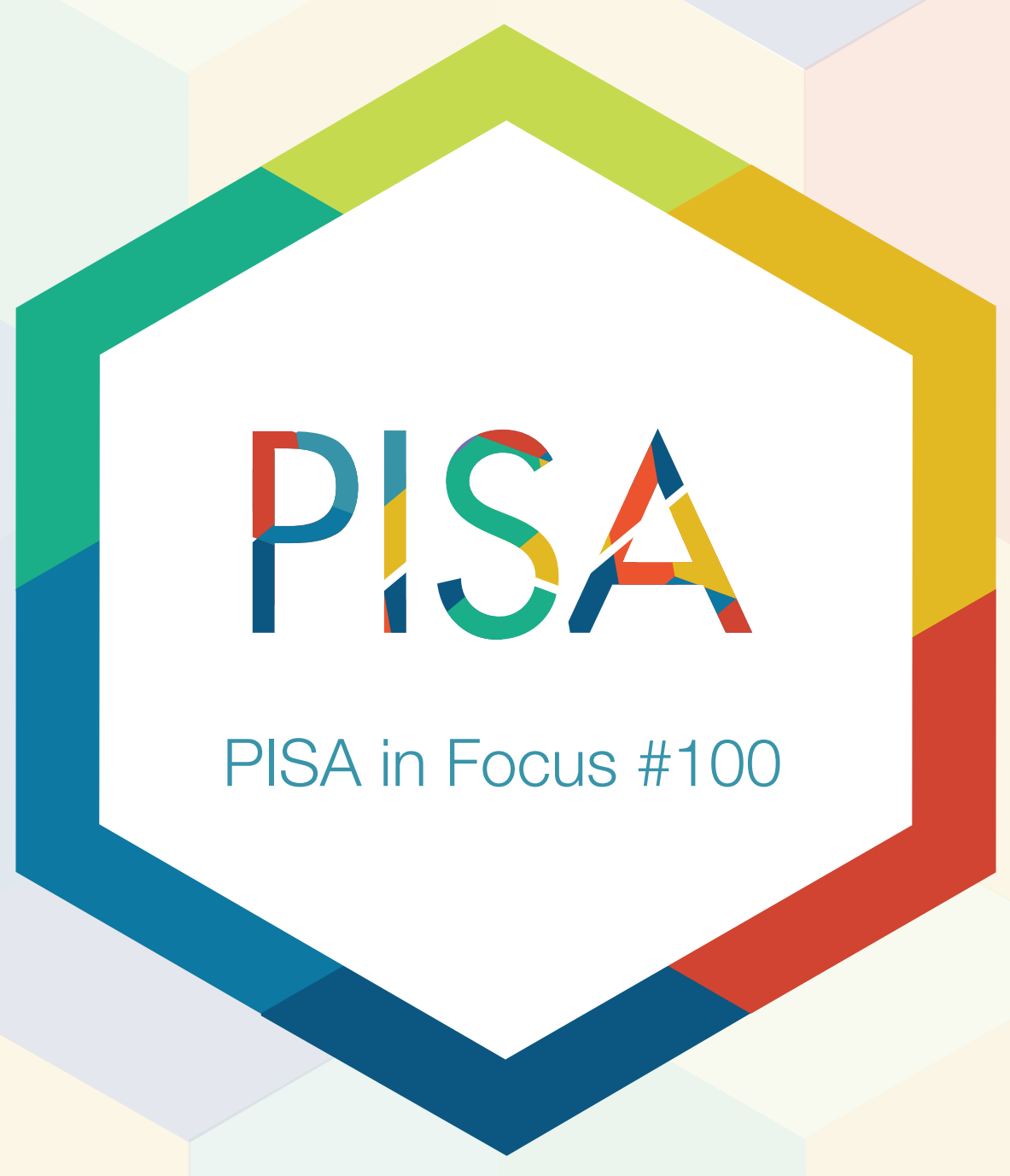




\section{Have students' feelings of belonging at school waned over time?}

- In 2015, the majority of students in all countries that participated in PISA reported that they feel they belong to the school community. However, in the vast majority of countries, students' sense of belonging at school had weakened since 2003.

- Students who reported that they feel like outsiders at school were, on average across OECD countries, about three times more likely to be unsatisfied with their lives compared with students who did not report so.

- Students who reported that they feel like outsiders scored 22 points lower in science than students who did not report so.

Most adolescents desire strong social ties and value acceptance, care and support from others. Many adolescents find friends and caring adults among members of the school community. As students go through a decisive period of their lives, discovering and redefining their identity, a strong sense of belonging at school can help them feel secure, and can support their academic and social development. Adolescents who feel that they are part of a school community are also more motivated to learn and, as a result, more likely to perform well at school.

But in recent years, many traditional communities formed around shared physical spaces - neighbourhoods, workplaces or schools - have been profoundly affected by advances in technology. How did students' feelings of belonging at school change over a period in which online friendships and social networks were growing in importance?

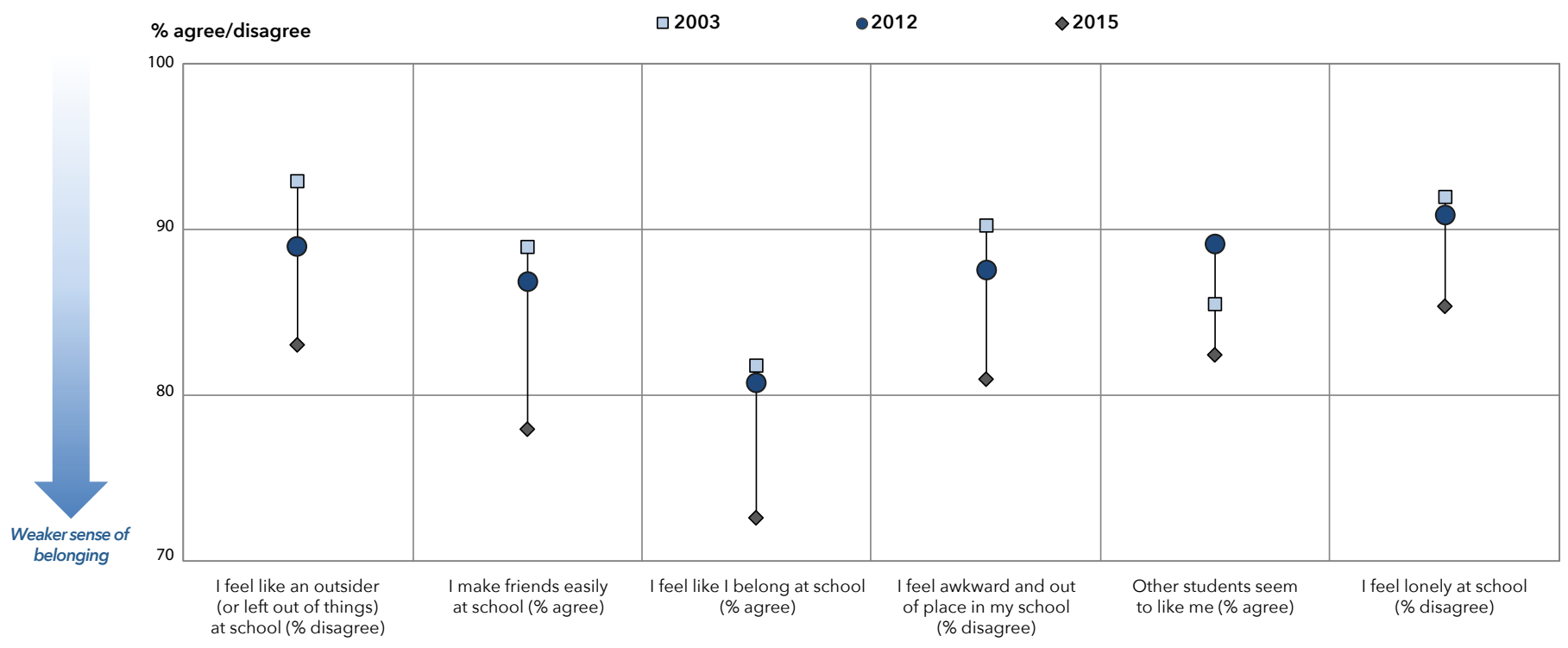

Notes: The OECD average reported in this figure does not include Chile, Colombia, Estonia, Israel, Lithuania, Slovenia and the United States due to missing data in PISA 2003. All changes between 2003 and 2015, and 2012 and 2015 are statistically significant.

Source: OECD (2017), PISA 2015 Results Nolume III): Students' Well-Being, Figure III.7.1; http://dx.doi.org/10.1787/888933471478 


\section{In a majority of OECD countries, the share of students who reported feeling out of place in their school increased.}

In order to measure students' sense of belonging at school, in 2003, 2012 and 2015 PISA asked students to report whether they "strongly agree", "agree", "disagree" or "strongly disagree" with six statements. A strong sense of belonging manifests itself as disagreement with three of these statements ("I feel like an outsider or left out of things at school"; "I feel awkward and out of place in my school"; "I feel lonely at school"), and as agreement with the remaining three statements ("I make friends easily at school"; "I feel like I belong at school"; and "Other students seem to like me").

Between 2003 and 2015, students' sense of belonging at school seems to have weakened. On average across 30 OECD countries with comparable data, over those 12 years the proportion of students who reported feeling like an outsider at school increased by 10 percentage points, from $7 \%$ to $17 \%$. Similarly, the proportion of students who reported feeling awkward and out of place in their school increased by 9 percentage points, and the proportion of students who reported feeling lonely increased by 7 percentage points. Significant increases in the proportion of students who agreed with these negative statements were observed in almost all countries. Among countries with comparable data, only Korea and Indonesia, for example, did not see an increase in the proportion of students who reported feeling like outsiders (or left out of things) at school. Related decreases in the proportion of students who agreed that they "make friends easily at school", "feel like [they] belong at school" and who reported that "other students seem to like [them]" were also observed in a majority of countries.

The reasons why students across so many countries feel less accepted, respected and supported by peers and adults in their school are unclear. In some European countries, increasingly larger shares of immigrant students may have contributed to less of a sense of belonging at school overall. Students with an immigrant

Change over 12 years in students feeling like an outsider at school

Change through 2003, 2012 and 2015 in the percentage of students who reported "disagree" or "strongly disagree" with the statement "l feel like an outsider (or left out of things) at school"

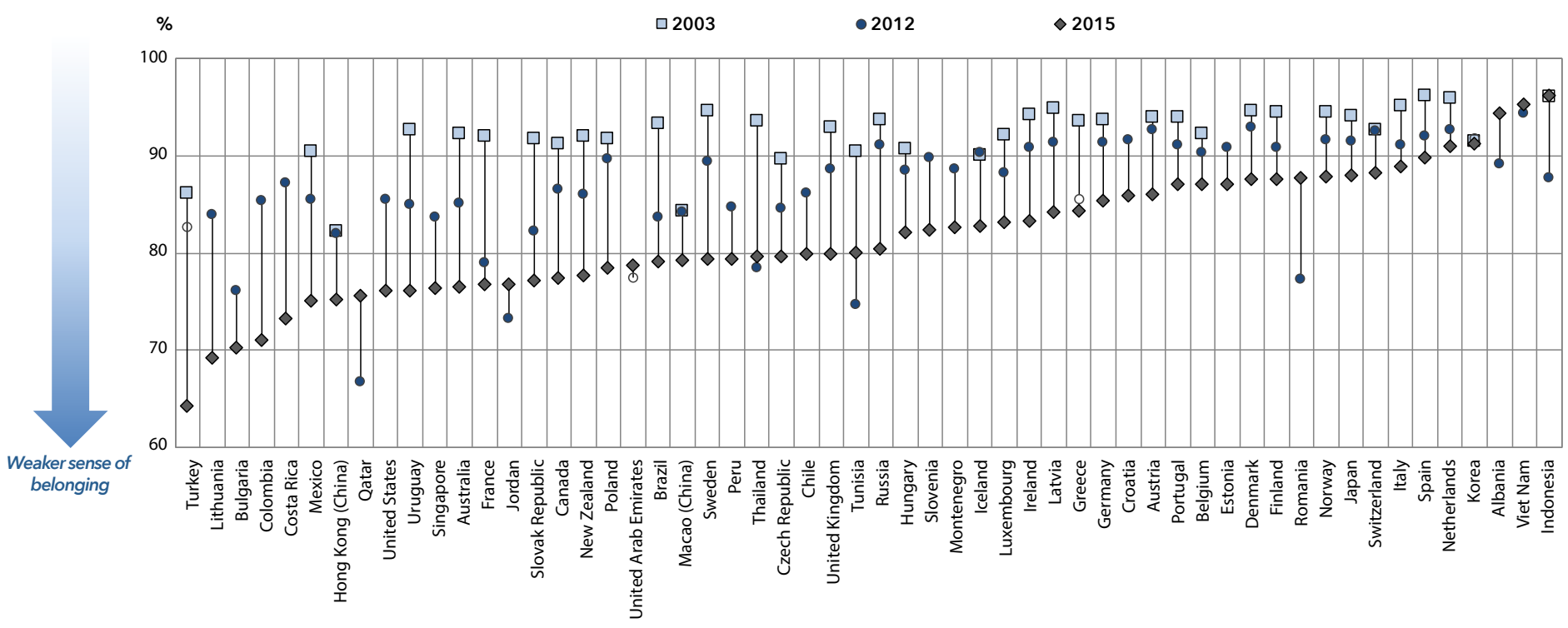

Notes: Coloured markers for 2003 and 2012 indicate significant differences with respect to 2015; hollow markers indicate non-significant differences.

Countries/economies are ranked in descending order of the percentage of students who reported feeling like an outsider at school in 2015.

Source: OECD (2017), PISA 2015 Results Nolume III): Students' Well-Being, Tables III.7.4 (http://dx.doi.org/10.1787/88933471288) and III.7.5 (http://dx.doi.org/10.1787/888933471292) 
Feeling like an outsider at school and low life satisfaction

Likelihood that students are not satisfied with their lives if they 'feel like an outsider at school", after accounting for students' and schools' socio-economic profile

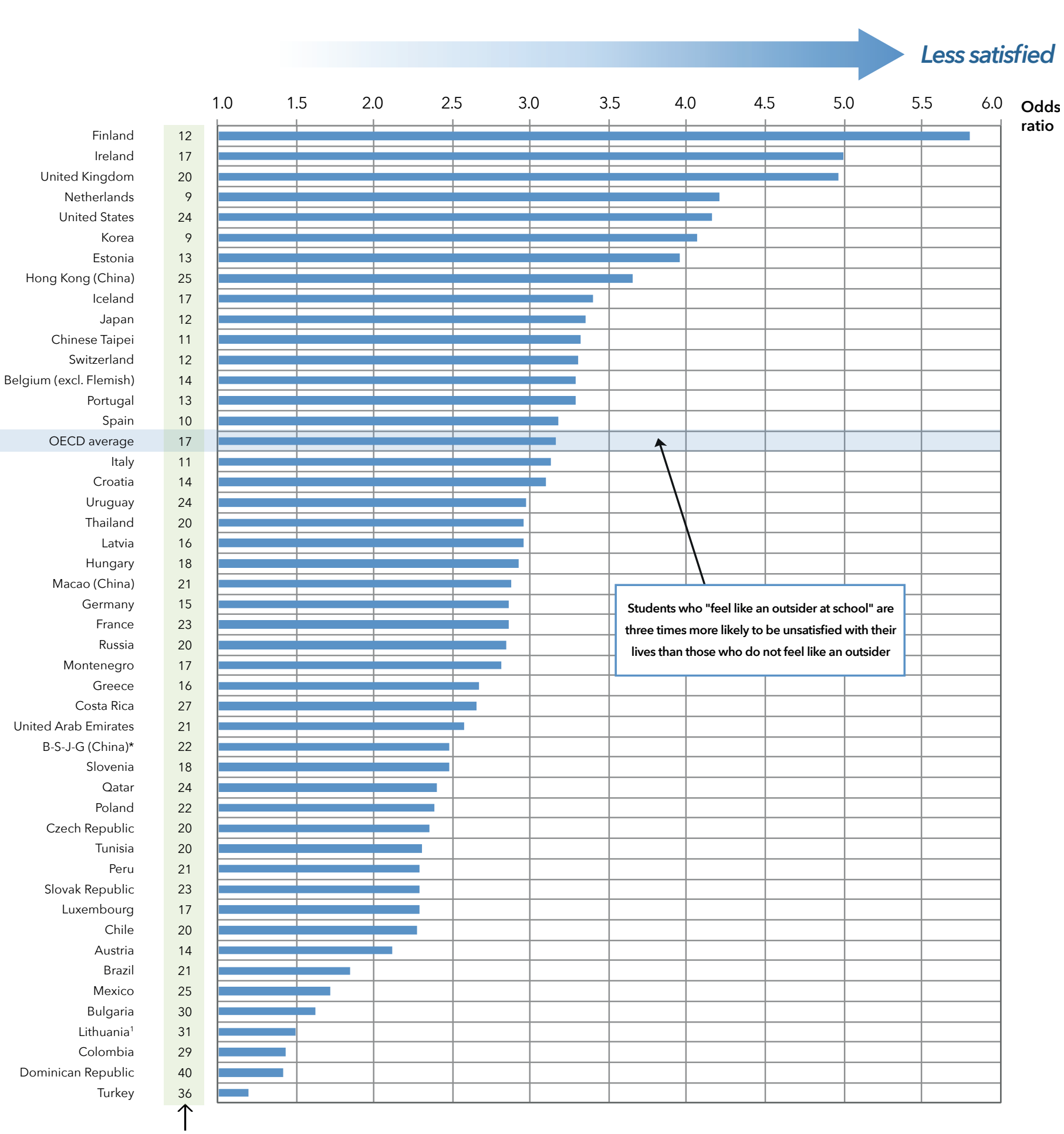

Percentage of students who feel like outsiders

${ }^{*}$ B-S-J-G (China) refers to the four Chinese provinces and municipalities that participated in PISA 2015: Beijing, Shanghai, Jiangsu and Guangdong 1. Lithuania became a member of the OECD on 5 July 2018. However, consistent with other publications based on PISA 2015 data, Lithuania is not included in the OECD average. Note: A student is classified as "not satisfied" if he or she reported a value between 0 and 4 on the life-satisfaction scale, which ranges from 0 to 10.

Countries and economies are ranked in descending order of the odds of reporting low life satisfaction, after accounting for students' and schools' socio-economic profile.

Source: OECD (2017), PISA 2015 Results (Volume III): Students' Well-Being, Figure III.7.5; http://dx.doi.org/10.1787/888933471518 
background in these countries often reported a weaker sense of belonging at school (in other countries, such as Australia, the opposite was true). However, a weakening sense of belonging was also observed in most European countries among non-immigrant students.

Perhaps, the waning sense of belonging at school reflects a more general decline of offline communities, as online social networks gain new prominence for forging friendships and expressing one's identity. Online communities offer new opportunities to many adolescents; but the time spent on line can also reduce the time spent in offline interactions with members of the school community, and can generate feelings of exclusion and fear of missing out among vulnerable adolescents. That this trend can be seen across many countries, and appears to accelerate after 2012 is consistent with the massive increase in mobile Internet services; but more evidence is needed to confirm this pattern. In 2018, PISA asked students the same questions about their sense of belonging at school. Results, to be revealed in December, will show whether the negative trend has continued, and may help disentangle some of these explanations.

\section{A weak sense of belonging at school is associated with lower academic achievement and life satisfaction.}

Whether they care mostly about students' academic outcomes, or more generally about their well-being, parents, teachers and policy makers are right to be worried about the increasing number of students who report a weak sense of belonging at school. Students who feel like outsiders at school are, on average, about three times more likely to be unsatisfied with their lives. They also score, on average, significantly below students who do not feel like outsiders - although this relationship may depend on the social desirability attached to academic achievement: there is no relationship, across countries, between the decline in sense of belonging and changes in average performance.

\section{The bottom line}

A weakening sense of belonging at school can negatively affect adolescents' satisfaction with life. To support students' sense of belonging at school, school administrators and teachers need to put in place strategies to identify those students who are most at risk of social exclusion, and provide them with the means to establish positive social ties with educators and peers. Strategies to promote well-being at school need not be limited to at-risk students; schools can, for example, encourage collaboration among students, teachers and parents to strengthen everyone's sense of belonging. 


\section{For more information}

Contact: Francesco Avvisati (Francesco.Avvisati@oecd.org)

See: OECD (2017), PISA 2015 Results (Volume III): Students' Well-Being, PISA, OECD Publishing, Paris https://doi.org/10.1787/9789264273856-en.

Coming next month: How does PISA 2018 assess 15-year-olds' reading literacy?

This paper is published under the responsibility of the Secretary-General of the OECD. The opinions expressed and the arguments employed herein do not necessarily reflect the official views of OECD member countries.

This document, as well as any data and map included herein, are without prejudice to the status of or sovereignty over any territory, to the delimitation of international frontiers and boundaries and to the name of any territory, city or area.

The statistical data for Israel are supplied by and under the responsibility of the relevant Israeli authorities. The use of such data by the OECD is without prejudice to the status of the Golan Heights, East Jerusalem and Israeli settlements in the West Bank under the terms of international law.

This work is available under the Creative Commons Attribution-NonCommercial-ShareAlike 3.0 IGO (CC BY-NC-SA 3.0 IGO). For specific information regarding the scope and terms of the licence as well as possible commercial use of this work or the use of PISA data please consult Terms and Conditions on www.oecd.org. 